Ampasavate, C., Chandorkar, G.A, VanderVelde, D., Stobaugh, J.F., and Audus, K.L. (2002) Transport and metabolism of opioid peptides across BeWo Cells, an in vitro model of the placental barrier. Int. J. Pharm. 233, 85-98. PMID: 11897413. Publisher's official version: <http://dx.doi.org/10.1016/S0378-5173(01)00929-2> . Open Access version: http://kuscholarworks.ku.edu/dspace/.

[This document contains the author's accepted manuscript. For the publisher's version, see the link in the header of this document.]

Paper citation: Ampasavate, C., Chandorkar, G.A, VanderVelde, D., Stobaugh, J.F., and Audus, K.L. (2002) Transport and metabolism of opioid peptides across BeWo Cells, an in vitro model of the placental barrier. Int. J. Pharm. 233, 85-98. PMID: 11897413

Abstract: In keeping with the advance of biotechnology, cell culture becomes an important tool for investigating the transport and the metabolism phenomena. A cell line of human origin, the BeWo choriocarcinoma cell line, was used for the study of the transport and metabolism of opioid peptides across the in vitro model of the placental barrier. Opioid peptides, both naturally occurring and their synthetic analogs, are of interest to be developed as potent analgesics and were included in this study. The apparent permeability coefficients of the peptides containing 4 to 11 amino acid or analog residues were in the range of $0.23-14.60 \times 10^{-5} \mathrm{~cm} / \mathrm{sec}$. The apparent permeability coefficients of these peptides were comparable to those of sucrose or dextrans, hydrophilic markers. Molecular weight and size of the peptides were inversely correlated to the permeability across the BeWo monolayers. Lipophilicity and charges of the peptides were also investigated and found to be the minor factors regulating the extent of peptide permeation. Contrasting to the transport of DPDPE peptide analog across the blood-brain barrier, the transport of DPDPE across the BeWo monolayers were not found to be via carrier-mediated transport. The major transport pathway of the opioid peptides across the BeWo monolayers was found to be via paracellular route. In metabolism studies, aminopeptidase was found to be a major enzyme type responsible for the degradation of naturally occurring peptides but not for the synthetic analogues. The finding obtained from the present study reveal the applicability of the BeWo cell line to be used as the in vitro cell culture model for the transport and metabolism screening of the opioid peptides.

Text of paper: 
For Submission to the Journal of Pharmaceutical Sciences

\title{
Transport and Metabolism of Opioid Peptides across BeWo Cells, An In Vitro Model of the Placental Barrier
}

\author{
Chadarat Ampasavate, Gurudatt A. Chandorkar, David Vande Velde, John F. Stobaugh \\ and Kenneth L. Audus
}

Address for correspondence:

Kenneth L. Audus, Ph.D.

Department of Pharmaceutical Chemistry

University of Kansas

2095 Constant Avenue

Lawrence, KS 66047 
Introduction

Since the discovery of multiple opioid receptors (1) and endogenous opioid peptides (2), several attempts have been made to synthesize safe and effective agonists to selective opioid receptors. The clinically used $\mu$-opioid receptor agonists such as morphine and meperidine are associated with side effects, which range from constipation to respiratory depression and dependence liability (3). In addition, the above mentioned $\mu$-receptor agonists have the ability to rapidly cross the placental barrier, thus posing a risk to the developing fetus.

The developing fetus is not known to express the $\delta$-opioid receptor (4). Therefore, selective $\delta$-opioid receptor analogues can be developed without the risk of any adverse effects to the fetus. The endogenous $\delta$-opioid receptor-specific enkephalins (leu and met-enkephalins) have been shown to have significant analgesic properties (2). However, due to their high susceptibility to enzymatic degradation in vivo, attempts are being made to synthesize highly selective, enzymatically stable analogues of enkephalins which can be clinically used in the treatment of pain. Mosberg et al. (5) reported the synthesis of several synthetic analogues of leu-enkephalin with high selectivity towards the $\delta$-opioid receptor. In addition, some of these peptides have shown good in vivo stability and appear to be promising candidates for the treatment of pain (6). The bloodbrain barrier (BBB) transport of one synthetic analogue of leu-enkephalin, DPDPE, was found to be carrier-mediated (7). However, no information currently exists on the placental transport and metabolism of these peptides. 
The primary function of the placenta is to transport nutrients and excretory products to and from the fetus. In addition, the placenta is also involved in the synthesis of hormones and steroids (8). Although passive diffusion is the principal mechanism of transport across the placenta (9), several carrier-mediated transport mechanisms (e.g. for glucose, fatty acids and amino acids) have been identified $(10,11)$. Several in vivo and in vitro models have been utilized to study the transport of substances across the placental barrier $(12,13)$. However, in vitro models provide a simple and rapid method of studying the mechanistic aspects of drug transport. Several cell lines (e.g. JAR, JEG and BeWo) have been evaluated for their potential applications in the study of the mechanisms of trans-trophoblast transport of drugs (14-16). The BeWo cell line is a choriocarcinoma cell line developed from a malignant gestational choriocarcinoma of the fetal placenta and was characterized in 1968 (17). This cell line has been shown to exhibit morphological and biochemical characteristics, similar to the human trophoblasts and the presence of nutrient and serotonin transporters (18-20) . In addition, the BeWo cell line is stable, easy to maintain by passage and forms confluent monolayers on polycarbonate filters in a relatively short period of time (4-5 days), making it an attractive in vitro model to study trans-trophoblast transport, uptake and metabolism of drugs.

Peptide transport across the placenta has not been studied extensively. Of the few reported studies, the primary mechanism of peptide transport across the placenta appears to be via paracellular diffusion (21). However, a low affinity transporter for dipeptides has been shown to exist (22). The objectives of the present work were to investigate the trans-trophoblast transport of a series of opioid peptides and to determine the effect of physico-chemical properties (molecular size, molecular weight and lipophilicity) on their 
transport across the trophoblast barrier. In addition, the susceptibility of the peptides to enzymatic degradation and the mechanisms of transport of one synthetic analogue (DPDPE) across the trophoblast monolayers were also investigated.

\section{Materials and Methods}

\section{Materials:}

Translucent polycarbonate filters (12 mm diameter, $0.4 \mu \mathrm{M}$ pore size) were obtained from Fisher Scientific. ${ }^{3} \mathrm{H}$-DPDPE and ${ }^{3} \mathrm{H}$-DAMGO were obtained from DuPont-NEN Research (Boston, MA). Amastatin ([(2S, 3R)-3-Amino-2-hydroxy-5methylhexanoyl]-Val-Val-Asp) was obtained from ICN (Cosa Mesta, CA). Leuenkephalin (LE) was purchased from Sigma (St.Louis, MO). All other peptides [Tyr-DArg-Phe-D-Leu-NH $\mathrm{NH}_{2}$ (DADLE), Tyr-Tic-Phe-Phe (TIPP), Tyr-Tic $\psi\left[\mathrm{CH}_{2}-\mathrm{NH}\right]-\mathrm{Phe}-\mathrm{Phe}$ (TIPP- $\psi)$, Dynorphin A (1-11), Dynorphin A (2-11), Dynorphin A (1-8), Tyr-D-Ala-GlyN-Me-Phe-Gly-ol (DAMGO), Tyr-D-Arg-Phe-Lys-NH2 (DALDA), Tyr-D-Ser-Gly-PheLeu-Thr (DSLET), and Tyr-[D-pen-Gly-Phe-D-Pen] (DPDPE)] were obtained from the National Institute on Drug Abuse (NIDA). Dulbecco's modified Eagles medium (DMEM), Hank's balanced salt solutions (HBSS) and trypsin/EDTA solutions were purchased from Sigma. Fetal bovine serum, heat activated (FBS/HI), was from JRH Biosciences (Lenexa, KS). Penicillin/streptomycin as a mixture was obtained from GIB/Co. (Gaithersburg, MD). Rat-tail collagen was prepared in our laboratory. For performing the sensitive determinations of peptides [LE, Dynorphin A (1-11), Dynorphin A (2-11), and Dynorphin A (1-8)], 1H-naphtho(2,3-d)imidazole-6,7-dicarboxaldehyde 
(IMNDA), a fluorogenic derivatizing reagent, was synthesized in our laboratory. Sodium cyanide $(\mathrm{NaCN})$ was purchased from Aldrich (St. Louis, MO). All other chemicals were of the highest, commercially available grade.

BeWo cell culture:

The BeWo clone (b30) was obtained from Dr. Alan Schwartz (Washington University, St. Louis, MO). The cells were cultured and harvested as previously described (23). For transport studies, the cells were passed onto polycarbonate membranes coated with rat tail collagen. At a seeding density of 100,000 cells $/ \mathrm{cm}^{2}$, the cells formed monolayers in 4-5 days. The medium was changed every other day and all cells used for these studies were from passages 35-90.

\section{Transmonolayer Permeability:}

Trans-monolayer permeability studies were carried out using a Side-Bi-Side ${ }^{\mathrm{TM}}$ diffusion apparatus (Crown Glass Company). The donor and receiver chambers were each filled with $3.0 \mathrm{ml}$ of PBSA (pH 7.4). The cells faced the donor chamber as the apical (maternal) side and the membranes faced the receiver chamber as the basolateral (fetal) side. The temperature during the studies was maintained at $37^{\circ} \mathrm{C}$ using thermostated water jacket. The contents of the two chambers were stirred continuously at 600 revolutions/min with magnetic stir bars to prevent the formation of an aqueous boundary layer. Prior to the studies, the monolayer cultures were equilibrated for 30 minutes. Experiments were initiated by adding either $5 \mathrm{nM}\left({ }^{3} \mathrm{H}-\mathrm{DPDPE}\right.$ and ${ }^{3} \mathrm{H}-$ DAMGO) or 100 
$\mu \mathrm{M}$ of the other peptides (dissolved in PBSA) to the donor chamber. A $100 \mu \mathrm{l}$ sample was obtained from the receiver chamber at different time points over a $60\left({ }^{3} \mathrm{H}\right.$-DPDPE and ${ }^{3} \mathrm{H}$-DAMGO) or 120 minute (all other peptides) period with replacement of the buffer after each sample withdrawal. Samples were analyzed by liquid scintillation spectrometry $\left({ }^{3} \mathrm{H}\right.$-DPDPE and ${ }^{3} \mathrm{H}$-DAMGO) using a Beckman scintillation counter (LS 6800) or by HPLC. In addition, transport experiments were conducted with ${ }^{14} \mathrm{C}$ - sucrose, a marker for paracellular transport. Polycarbonate membranes treated with rat-tail collagen but without cell monolayers were used as a control. The apparent permeability coefficients were estimated using the following equation:

$$
P(\mathrm{~cm} / \mathrm{s})=X /\left(A * t * C_{d}\right)
$$

Where $\mathrm{P}$ is the apparent permeability coefficient, $\mathrm{X}$ is the amount of substance (mol) in the receiver chamber at time $t(\mathrm{~s}), \mathrm{A}$ is the diffusion area $\left(0.636 \mathrm{~cm}^{2}\right)$ and $\mathrm{C}_{\mathrm{d}}$ is the concentration of the substance in the donor chamber $\left(\mathrm{mol} / \mathrm{cm}^{3}\right)$. The permeability coefficients were expressed as the mean \pm SD from three to six different monolayers.

The apparent permeability coefficients for the BeWo monolayers , $\mathrm{P}_{\mathrm{e}}$, were calculated from the following relationship;

$$
1 / P_{t}=1 / P_{c}+1 / P_{e}
$$

where $\mathrm{P}_{\mathrm{t}}$ is the apparent permeability coefficients for the collagen-coated polycarbonate membranes in the presence of BeWo cell monolayers and $\mathrm{P}_{\mathrm{C}}$ is the apparent permeability coefficients for collagen-coated polycarbonate membranes alone (24).

In order to determine the mechanism of DPDPE transport across the BeWo monolayers, transport experiments $(n=4-6)$ of $5 \mathrm{nM}{ }^{3} \mathrm{H}$-DPDPE were carried out in the presence of excess (300 $\mu \mathrm{M})$ unlabelled DPDPE. In addition, to ensure that DPDPE was 
not being metabolized by the enzymes of the BeWo cells during its transport, separate transport studies of ${ }^{3} \mathrm{H}$-DPDPE were conducted in the presence of an aminopeptidase inhibitor, amastatin (300 $\mu \mathrm{M})$. Apparent permeability coefficients for DPDPE were calculated in the presence and absence of amastatin.

\section{HPLC Analysis:}

Analysis of three peptides (DALDA, DADLE and DSLET) was conducted using reverse phase HPLC with UV detection. Samples (30 $\mu$ l in triplicate) were injected on a 4.5 X 250 mm C-18 column (Waters, Milford, MA) by an autoinjector (Shimadzu SIL-10 AD). The mobile phase consisted of a mixture of $0.1 \mathrm{M} \mathrm{NaH}_{2} \mathrm{PO}_{4}$ (containing $0.1 \%$ heptanesulfonic acid) and acetonitrile (75:25 v/v), $\mathrm{pH} 3.0$ at $37^{\circ} \mathrm{C}$ at a flow rate of 1.5 $\mathrm{ml} / \mathrm{min}$. The eluting peptides were detected at a wavelength of $210 \mathrm{~nm}$ using a Shimadzu UV detector (SPD 6A)

For performing a sensitive determination, reversed-phase HPLC with precolumn derivatization was optimized to determine the concentrations of LE and dynorphins. The peptides were treated with IMNDA/NaCN to form fluorescent products. Subsequently, an aliquot of $50 \mu \mathrm{l}$ of reaction mixture was injected onto HPLC column. Details of the analytical method were describes elsewhere (25). A Spherisorb ${ }^{\circledR}$ ODS (5 $\mu \mathrm{M}, 80 \AA, 250$ x $4.6 \mathrm{~mm}$ ) column (Alltech, Deerfield, IL) was used for the determination of LE- and dynorphin-IMNDA(CN) derivatives. Gradient elution with solution A [10\% acetonitrile (ACN) in 0.05\% TFA and $20 \mathrm{mM}$ 1-heptane sulfonic acid (HSA)] and solution B [10\% of $0.05 \%$ TFA and $20 \mathrm{mM}$ 1-heptane sulfonic acid (HSA) in ACN] was performed with a linear gradient of $37 \%$ to $77 \%$ of solvent B within 20 minutes. For 
TIPP and TIPP- $\psi$ determinations, an in-house packed Hypersil ${ }^{\circledR} \mathrm{C} 18$ (5 $\mu \mathrm{M}, 80 \AA ⿻, 150 \mathrm{x}$ $4.6 \mathrm{~mm}$ ) was used in the study. Isocratic elution with $28 \%$ ACN in $26 \mathrm{mM}$ trifluoroacetic acid (TFA) was employed to elude the native form of TIPP and TIPP- $\psi$. All separations were performed at an ambient temperature at the flow-rate of $1.0 \mathrm{ml} / \mathrm{min}$. Fluorescence detection was the technique employed either at $\lambda_{\mathrm{ex}}=467 \mathrm{~nm}$ and $\lambda_{\mathrm{em}}=510 \mathrm{~nm}$ for the IMNDA derivatives or at $\lambda_{\mathrm{ex}}=208 \mathrm{~nm}$ and $\lambda_{\mathrm{em}}=305 \mathrm{~nm}$ for the native TIPP and TIPP$\psi$ peptides.

Stability of Opioid Peptides upon Exposure to the BeWo Monolayers:

The BeWo cells were seeded at 100,000 cells $/ \mathrm{cm}^{2}$ into the 12 well tissue culture plates. Collagen-coated polycarbonate membranes were not required in this study. Cell maintenance was performed as described earlier; however, care was taken due to an easier detachment of the cell membranes from the plastic surface than the surface of the collagen-coated polycarbonate filters. Since fully-grown or aged cells will detach easily from the plastic surface, the metabolism study was performed after the cells had grown to cover about $90 \%$ of the total surface. The cell monolayers were washed 3 times with $37^{\circ} \mathrm{C}$ phosphate buffer saline-ascorbic acid (PBSA) solution to eliminate other primary amines such as amino acids in cell culture media or other peptides that cells might have released to the medium. Subsequently, the tissue culture plates were incubated in a temperature-controlled shaking water-bath $\left(60 \mathrm{rpm}, 37^{\circ} \mathrm{C}\right)$ for 10 minutes. Afterward, a peptide solution $(25.0 \mu \mathrm{M})$ was added to each well including control wells, the wells without BeWo cell monolayers present. Immediately after the addition of the peptide solution, peptide aliquots were withdrawn for the initial concentration 
determination. At 5, 15, 30, and 60 minutes, $176 \mu$ l aliquots were pipetted out from the subsequent wells. The samples were collected in polypropylene vials and were then frozen immediately until the analysis.

\section{Lipophilicity:}

Utilization of the capacity factor $\left(\mathrm{k}^{\prime}\right)$ from reversed-phase high-performance chromatography (RP-HPLC) has been reported for lipophilicity measurement (26, 27). In this study, the relative lipophilicity of the opioid peptides was determined from the ability of the peptides to interact with the immobilized artificial membrane (IAM). An IAM chromatography column (4.6mm i.d. x 100 mm, $5 \mu \mathrm{m}, 300 \AA$, Regis Technologies, Inc., Morton Grove, IL) with 5-10\% ACN in $10 \mathrm{mM}$ phosphate buffer as a mobile phase was used in determining of the ability of the peptides to interact with phosphatidylcholine (PC) analog membranes. The PC analog membranes are the artificial membrane mimic the lipid environment found in cell membrane $(28,29)$. A $20 \mu \mathrm{l}$ aliquot of each peptide solution $(100 \mu \mathrm{M})$ was injected on the column (flow rate $1.0 \mathrm{ml} / \mathrm{min}$ ), and the eluate was detected with the UV (210 nm) detector (Shimadzu, Columbia, MD). The IAM capacity factors $\left(k_{\text {IAM }}^{\prime}\right)$ of the opioid peptides were calculated from the following equation:

$$
k_{\text {IAM }}^{\prime}=\frac{t_{R}-t_{0}}{t_{0}}
$$

where $t_{R}$ is the retention time of a peptide and $t_{0}$ is the column void volume. Permeability coefficients were plotted against the $k_{\text {IAM }}^{\prime}$ of the opioid peptides in order to evaluate the relationship between the relative lipophilicity of the peptides and ability to cross the BeWo monolayers. 
Molecular Size:

${ }^{1} \mathrm{H}-\mathrm{NMR}$ spectroscopy was utilized to determine the diffusion coefficients of the opioid peptides and analogues. An opioid peptide in a concentration of $1 \mathrm{mM}$ was dissolved in $10 \% \mathrm{D}_{2} \mathrm{O}$ and $90 \% \mathrm{H}_{2} \mathrm{O}$. A $500 \mathrm{MHz}$ NMR spectrometer (Bruker AM-500) interfaced to an auxiliary PC-driven 15 ampere gradient pulse generator specifically designed for diffusion studies (Digital Specialties, Chapel Hill, NC) was employed in this study. The NMR spectra were acquired using the pulsed field gradient bipolar longitudinal eddy current delay pulse sequence. During the experiments, the diffusion delay time was held constant at $200 \mathrm{msec}$ and the gradient pulse duration at $2 \mathrm{msec}$. The gradient pulses was sequentially increased (i.e., 0.9, 1.4, 1.8, 2.6, 3.4, 4.2, 5.0 and 5.6 msec) until one order of magnitude decreasing of a peak height of interest was observed. The experimental gradient strength was calculated from a coil constant of $5.15 \mathrm{G} / \mathrm{cm} / \mathrm{A}$ based on the known diffusion coefficient of $\beta$-cyclodextrin at $25^{\circ} \mathrm{C}, 3.23 \times 10^{-6} \mathrm{~cm}^{2} / \mathrm{sec}$. By linear regression analysis, the diffusion coefficients at $25^{\circ} \mathrm{C}$ were obtained from the slope of the semilogaritm plots of the peak height versus the square of the pulse gradient. Applying the Stokes-Einstein equation, molecular radii (radius of gyration) of the peptides were calculated from their diffusion coefficients determined from the NMR experiments (30):

$$
D=k T / 6 \pi \eta r \quad \text { (Stokes-Einstein equation) }
$$

where $D$ is the diffusion coefficient ( $\left.\mathrm{m}^{2} / \mathrm{sec}\right), k$ is Boltzmann's constant, $T$ is the absolute temperature $(\mathrm{K}), r=$ the radius of a spherical particle and using viscosity $(\eta)=0.9183$ 
centipoises calculated from the standard $D$ and $\eta$ of water at $25^{\circ} \mathrm{C}$ and $D$ of $10 \% \mathrm{D}_{2} \mathrm{O}$ and $90 \% \mathrm{H}_{2} \mathrm{O}$ at $25^{\circ} \mathrm{C}$ according to the square-root of mass law (31-33).

\section{$\underline{\text { Results and Discussion: }}$}

\section{Molecular Weight and Size of Peptides vs. Permeability Coefficients:}

Several in vivo and in vitro models have been used to study the trans-placental transport of nutrients and drugs $(16,34-36)$. However, in vitro models could provide greater benefits in terms of speed and ease in the determination of the transport mechanisms and metabolism across barriers. The BeWo cell culture model has been shown to have morphological and biochemical characteristics similar to the human trophoblasts. Unlike the placental primary cell cultures, the BeWo cell can be grown to confluent monolayers on rat tail collagen coated polycarbonate membranes with 4-5 days. These properties make the BeWo cell culture model an attractive in vitro model to study mechanisms of trans-trophoblast transport and metabolism of drugs.

Although very few studies have been conducted, peptide transport across the placenta appears to be primarily via passive diffusion (21). The placenta, unlike the gastro-intestinal or the blood-brain barrier is a 'leaky' barrier and allows for a relatively free exchange of substances. The apparent permeability coefficients of most of the peptides studied (Table 1) were in the same range of the permeability coefficients of hydrophilic markers $\left[{ }^{14} \mathrm{C}\right.$-sucrose, fluorescein and fluorescein isothiocyanate conjugated dextrans (FITCDs). The effect of peptide size was clearly shown to be an important factor in the transport study of dynorphin A series (1-11, 2-11 and 1-8), (Figure 1). 
Dynorphin A (1-11) (M.W. 1363) was the least permeable across the BeWo monolayers. The inverse correlation between the $\mathrm{P}_{\mathrm{e}}(\mathrm{s})$ and molecular weight (M.W.) of the peptides shown in Figure 2 indicates that the permeability of the peptides was highly dependent on their molecular weights and thus, their diffusivity in water. Concerning various conformations of peptides in an aqueous solution, an investigation of the relationship between peptide permeability and their size may give more meaningful comparison than the correlation of their molecular weights. Figure 3 shows the relationship between the apparent permeability coefficients and the molecular radii of the peptides determined from their diffusion coefficients using NMR spectroscopy technique. Similar to the relationship between the permeability coefficients and the molecular weights, inverse linear correlation was observed. The peptides with molecular weight $>800$ daltons or molecular radii $>6 \AA$ exhibit restricted permeation across the membranes. For smaller peptides, poor relationships were found when either molecular weights or molecular size was employed indicating other factors such as lipophilicity, hydrogen bonding or peptide charge may influence the permeation properties of the peptides. The excellent linear correlation between molecular weight and molecular radii of the peptides $\left(\mathrm{R}^{2}=0.9444\right)$ suggesting molecular weight could be used interchangeably with molecular size as the parameter for the prediction of peptide permeability across the BeWo monolayers.

\section{Lipophilicity vs. Permeability Coefficients:}

Lipophilicity is another parameter that was investigated. Immobilized artificial membrane (IAM) chromatography was selected to investigate the relative lipophilicity of the peptides. IAM chromatography was employed for the evaluation of lipophilicity and 
oral absorption ability of various drugs (29). However, the utilization of this column is not suitable for the investigation of basic peptides such as dynorphin A (1-11), (2-11), (18) and DALDA. Although this column is filled with an end-capped packing material, the residual adsorption of positively charges of the basic peptides to the free silanol groups or perhaps to the negative charges of phosphate head groups of phosphatidylcholine analogs could be observed from the broad peaks of the basic peptides. Figure 4a. shows the plot between the capacity factor $\left(\mathrm{k}_{\text {IAM }}\right.$ ) and the permeability coefficients of the opioid peptides. A $10 \% \mathrm{ACN}$ in $10 \mathrm{mM}$ sodium phosphate, $\mathrm{pH} 7.4$ was used as the mobile phase. The results from these conditions are misleading, since the peptides containing multiple positive charges [i.e., dynorphin $\mathrm{A}(\mathrm{s})$ ] were categorized as lipophilic compounds. By including $2 \mathrm{mM}$ 1-heptane sulfonic acid in an acidic mobile phase (10 $\mathrm{mM}$ sodium phosphate buffer, $\mathrm{pH}$ 3.0), the ionic interactions between the positive charges of the peptides and the stationary phase were suppressed. As shown in Figure 4b., more reasonable results indicating TIPP, TIPP- $\psi$ and a cyclic peptide (DPDPE) possessed lipophilic property were obtained. A trend-line was drawn to show the relationship between $\mathrm{k}_{\text {IAM }}^{\prime}$ of lipophilic peptides and their permeability coefficients. Contrasting to the trend observed from the permeability across gastrointestinal (GI) barrier in which the more lipophilic compounds have greater permeability across the GI barrier (29), the inverse correlation of the $\mathrm{k}_{\text {IAM }}$ and the permeability across the BeWo monolayers was observed in this study. In summary, the IAM column may not be appropriate for the determination of lipophilicity of basic compounds, since the interactions of analytes and stationary phase may cause false interpretations. It may also be unsuitable for the prediction of the compounds which permeate through water-filled 
channels, since the transport via this pathway is independent of the lipophilicity of analytes. This finding suggests that the transport mechanism via transcellular route is not a major pathway for the permeation of peptides across the BeWo monolayers.

As the peptides included in our study are relatively hydrophilic and their $\mathrm{P}_{\mathrm{e}}(\mathrm{s})$ are comparable to those hydrophilic markers, restricted diffusion through water-filled transmembrane channels or pores which is a primary transport mechanism of most hydrophilic substances was suggested to be a major transport mechanism for these peptides. In general, water-soluble drugs with molecular weights below 800 daltons (37) and perhaps closer to 1000 daltons $(21,38)$ appear to passively diffuse across the human placenta. Similarly, the peptides included in our study whose molecular weights are higher than 1000, such as dynorphin A (1-11), (2-11) and (1-8), encountered some permeability difficulties due to a sieving property of the membrane. These observations implied that the BeWo cell monolayers described by Liu et al. (23) are likely to have similar permeability properties, such as pore size and porosity, to the human placental membrane.

Due to the hydrophilic nature of these peptides, it is unlikely for them to be transported via a transcellular mechanism. However, additional experiments were carried out to determine whether a carrier-mediated mechanism exists in the trans-trophoblast transport of the opioid peptides. Williams et al.(7) reported the presence of a saturable transport system involved in the BBB transport of DPDPE. Therefore studies were initiated to determine the trans-trophoblast transport of DPDPE using the in vitro cell culture model. The placenta is known to have significant amounts of peptidase activity $(39,40)$. Although DPDPE has been shown to be stable against enzymatic degradation, 
the transport of ${ }^{3} \mathrm{H}$-DPDPE was studied in the presence of amastatin $(50 \mu \mathrm{M})$. As seen from the data (Figure 5), the permeability coefficients of ${ }^{3} \mathrm{H}$-DPDPE were not influenced by the presence of an excess amount $(300 \mu \mathrm{M})$ of unlabelled DPDPE or amastatin $\left[(\mathrm{p}<0.05)\right.$ from ${ }^{3} \mathrm{H}$-DPDPE alone]. These studies show that DPDPE is resistant to enzymatic hydrolysis by the placenta and it's primary mechanism of transport across the placenta is via passive diffusion.

Although a number of observations had been reported about the transport systems of nutrients and electrolytes across the placenta $(37,41)$, very limited information is available on peptide transport. To date, one uptake study reported on the presence of very low affinity dipeptide transporter(s) found in brush-border membrane vesicles (BBMV) prepared from human full-term placenta (22). However, these peptide transporters were not responsible for peptide uptake into human placental BBMV. A simple diffusion mechanism was also suggested to be a transport pathway of oxytocin from the study using in vitro dually perfused isolated cotyledons from term human placenta (21). While the other types of transport mechanisms remain unclear, an observation from our study suggested a possibility of the peptide transport via a transcellular route. For all of the peptides included in this study, less than ten percent of the total amount of the peptides were observed in the receiver chambers. Unlike other hydrophilic peptides, the permeation of rather lipophilic peptides, TIPP- $\psi$ and TIPP, was observed with the lag-times of 5 and 30 minutes for TIPP- $\psi$ and TIPP permeation, respectively. From mass balance consideration, the recovery of most peptides was approximately one hundred percent; except for TIPP. About 18\% of TIPP were lost from the initial amount. These observations suggested that a partial amount of TIPP could 
remain adhered to the membrane and/or in the cells, implying that the transcellular transport could be a pathway for relatively hydrophobic peptides, such as TIPP in this case.

Berhe et al. (42) reported the importance of charge effects on the permeability of positive or negative horseradish peroxidase across guinea-pig placenta. Positively charged protein was found to permeate across the placenta better than the negatively charged protein. However, no relationship between the charges and the permeability coefficients for the peptides was observed in this study. Therefore, the changes of maternal and fetal plasma $\mathrm{pH}$ would not be expected to affect the permeability of these peptides.

Stability of Opioid Peptides upon Exposure to BeWo Cell Monolayers:

Aminopeptidases, carboxypeptidases, endopeptidases and dipeptidases were previously reported to be the enzymes responsible for degrading peptides in the human placenta. Widely distributed in different parts of the placental cells, the transports of both naturally occurring and synthetic peptides are largely inhibited by peptidases (39, 40, 43). In this study, the naturally occurring opioid peptides, leu-enkephalin, dynorphin A (1-11) and the synthetic peptides, DADLE, TIPP and TIPP- $\psi$, were incubated with the BeWo cell monolayers at $37^{\circ} \mathrm{C}$. The surface area of a 12 -well plate used in the metabolism study was larger than the surface area of Side-Bi-Side ${ }^{\mathrm{TM}}$ diffusion unit, and the degradation of the naturally occurring peptides became significant. In the case of LE, although more than one site of the peptide bonds of LE is vulnerable to the enzymatic degradation, the major metabolite observed on the chromatogram was identified to be 
des-Tyr-leu-enkephalin. Des-Tyr-leu-enkephalin was also a primary metabolite of leuenkephalin found in rat jejunum (44) and in brain microvessel endothelial cells (BMEC) (45). Rapid degradation was also observed for the dynorphin A (1-11), another naturally occuring opioid peptide (Figure 6). The half-life of the intact dynorphin A (1-11) was found to be about 15 minutes. The presence of aminopeptidases in the BeWo cells was also confirmed in this study. The dynorphin A (1-11) was rapidly converted to several small fragments including des-Tyr peptide [dynorphin A (2-11)], which was the major identifiable metabolite. The dynorphin A (2-11) was subsequently metabolized to other unidentified fragments. Contrasting to the observation in plasma, dynorphin A (1-13) were $80 \%$ metabolized by carboxypeptidases (46), yielding dynorphin A (1-12). In this study, dynorphin A (1-10) was found to be insignificant amounts upon the exposure of dynorphin A (1-11) to the BeWo cells, suggesting that aminopeptidases are the major enzymes in this cell type. The peptidase activity in the BeWo cells was reported to be comparable to the activity in the placental cells from the primary cultures of the human cytotrophoblasts, however; the presence of gestation time, environment, smoking habits, drugs, metal and hormonal factors were shown to be important to the activity of the peptidases(40, 43). In contrast to the naturally occurring peptide counterparts, the synthetic peptides, DADLE, TIPP and TIPP- $\psi$, were more stable upon incubation with the BeWo cells (Figure 7). Therefore, the incorporation of unnatural amino acid residues into the peptide structures gave the peptides more resistance to placental enzyme degradation. However, awareness should be made when the chemical modification of the peptide structure was adopted, since the ability of peptides to bind with opioid receptors is highly dependent on peptide stereochemistry (47). The introduction of D-amino acid 
residue(s) may compromise or change the binding selectivity to the receptors. In addition, the presence of varieties of peptidases that can cleave at different sites of peptides increases the challenges to employ the chemical modification approach for the enhancement of peptide stability against enzymatic degradations.

\section{Conclusions:}

The BeWo cells served as both metabolic and physical barriers to the permeation of the peptides. The permeation across the BeWo monolayers was highly dependent on molecular weights and molecular size of the peptides but not their lipophilicity and charge characters. Therefore, the passage through the paracellular route was suggested to be a primary pathway for the transport of hydrophilic peptides. However, the presence of peptidases in BeWo cells largely inhibited the distribution of the peptides across the BeWo placental barrier. This study has confirmed the stability of structurally modified peptidomimetics in which peptides containing D-amino acid or unnatural residues were found to resist enzymatic degradation upon incubation with the BeWo cells. Finally, information from this study can help explain the ability of peptides to penetrate the placental barrier and provides a basis for future designs of peptide molecules with minimal penetration through the placental barrier and minimal side-effects for obstetric analgesic applications. 


\section{References:}

(1) Lord, J. A., Waterfield, A.A., Hughes, J., and Kosterlitz, H.W. Nature 1977, 267, 495-499.

(2) Hughes, J., Smith, T.W., Kosterlitz, H.W., Fothergill, L.A., Morgan, B.A., and H.R. Morris, H.R. Nature 1975, 258, 577-580.

(3) Galligan, J. J., Mosberg, H.I., Hurst, R., Hruby, V.J., and Burks, T.F. J.Pharmacol.Exp.Ther 1984, 229, 641-648.

(4) Rapaka, R. S., and Porreca, F. Pharm.Res 1991, 8, 1-8.

(5) Mosberg, H. I., Hurst, R., Hruby, V.J., Galligan, J.J., Burks, T.F., Gee, K., and Yamamura, H.I. Life Sci. 1983, 32, 2565-2569.

(6) Greene, D. L., Hau, V.S., Abbruscato, T.J., Bartosz, H., Misicka, A., Lipkowski, A.W., Hom, S., Gillespie, T.J., Hruby, V.J., and Davis, T.P. J.Pharmacol.Exp.Ther 1996, 277, 1366-1375.

(7) Williams, S. A., Abbruscato, T.J., Hruby, V.J., and Davis, T.P. J.Neurochem 1996, 66, 1289-1299.

(8) Chao, S. T., and Juchau, M.R. In Handbook of Experimental Pharmacology; Kochlar, E. M. J. a. P. M., Ed.; Springer-Verlag: Berlin, 1983; Vol. 31-48.

(9) Mirkin, B. L. Anesthesiology 1975, 43, 156-170.

(10) Lemons, J. A., Adcock, E.W., Jones, M.J., Naughton, M.A., Meschia, G., and Battaglia, F.C. J.Clin.Invest. 1976, 58, 1428-1434.

(11) Lemons, J. A., and Schreine, R.L. Am.J.Physiol. 1983, 244, E459-E466.

(12) Ringler, J. F., and Strauss, G.E. Endocr.Rev. 1990, 11, 105-123. 
(13) Schenker, S., Dicke, J., Johnson, R.F., Mor, L.L., and Henderson, G.I. J.Clin.Invest. 1987, 80, 1428-1434.

(14) Kulantaivel, P., Cool, D.R., Ramamoorty, S., Mahesh, V., Leibach, F.H., and Ganapathy, V. Biochem.J. 1991, 277, 53-58.

(15) Patillo, R. A., Ruckert, A., Hussa, R., Berstein, R., and Delfs, E. In Vitro 1971, 6, 398-404.

(16) Zevin, S., Schaner, M.E., Illsley, N.P., and Giacomini, K.M. Pharm.Res 1997, 14, 401-405.

(17) Patillo, R. A., and Gey, G.O. Cancer Res. 1968, 28, 1231-1237.

(18) Eaton, B. M., and Soorna, S.R. Placenta 1996, 17, 209-215.

(19) Prasad, P. D., Hoffmans, B.J., Moe, A.J., Smith, F.H., Leibach, F.H., and Ganapathy, V. Placenta 1996, 17, 201-207.

(20) Van der Ende, A., du Maine, A., Schwartz, A.L., and Strous, G.J. Biochem.J 1990, 270, 451-457.

(21) Malek, A., Blann, E., and Mattison, D.R. J.Matern.Fetal Med 1996, 5, 245-255.

(22) Meredith, D., and Laynes, R.W. Placenta 1996, 17, 173-179.

(23) Liu, F., Soares, M.J., and Audus, K.L. Am.J.Physiol. 1997, 273, C1596-C1604.

(24) Adson, A., Raub, T.J., Burton, P.S., Barsuhn, C.L., Hilgers, A.R., Audus, K.L.and Ho, N.F. J.Pharm.Sci. 1994, 83, 1529-1536.

(25) Ampasavate, C., Siahaan, T.J., Carlson, R.G. and Stobaugh, J.F. (submitting to J. Chromatogr. B).

(26) El-Tayar, N., van de Waterbeemd, H., and Testa, B. J. Chromatogr. 1985, 320, 293-304. 
(27) El-Tayar, N., van de Waterbeemd, H., and Testa, B. J. Chromatogr. 1985, 320, 305-312.

(28) Pidgeon, C., Ong, S., Liu, H., Qiu, X. Pidgeon, M. Dantzig, A.N. Munroe, J., Hornback, W.J., Kasher, J.S., Glunz, L., and Szczerba, T. J. Med. Chem. 1995, 38, 590-594.

(29) Ong, S., Liu, H., Qiu, X., Bhat, G., and Pidgeon, C. Anal.Chem. 1995, 67, 755762.

(30) Edward, J. T. J. Chem. Edu. 1970, 47, 261-270.

(31) Holz, M., and Weingartner, H. J. Magn. Reson. 1991, 92, 115-125.

(32) Holz, M., Mao, X., Seiferling, D., and Sacco, A. J. Chem. Phys. 1996, 104, 669679.

(33) Weast, R. C., and Astle, M.J. CRC Handbook of Chemistry and Physics, 63rd ed.; CRC Press: Boca Raton.

(34) Schneider, H., Panigel, M., and Dancis, J. Am.J.Obstet.Gynecol. 1972, 114, 822828.

(35) Schneider, H., and Dancis, J. Am.J.Obstet.Gynecol. 1974, 120, 1092-1096.

(36) Zevin, S., Schaner, M.E., and Giacomini, K.M. J.Pharm.Sci. 1998, 87, 702-706.

(37) Morriss, J. F. H., Boyd, R.D.H., and Mahendran, D. In The Physiology of Reproduction; E. Knobil, a. J. D. N., Ed.; Raven Press: New York,, 1994, pp 813861.

(38) Willis, D. M., O'Grady, J.P., Faber, J.J., and Thornburg, K.L. Am. J. Physiol. 1986, 250, R459-R464. 
(39) Gossrau, R., Graf, R., Ruhnke, M., and Hanski, C. Histochemistry 1987, 86, 405413.

(40) Shimamori, Y., Watanabe, Y., and Fujimoto, Y. Biochem.Med.Metab.Biol. 1988, 40, 305-310.

(41) Faber, J. J., and Thornburg, K.L. Placental Physiology: Structure Function and Fetomaternal Exchange; Raven Press: New York, 1983.

(42) Berhe, A., Bardsley, W.G., Harkes, A., and Sibley, C.P. Placenta 1987, 4, 365380.

(43) Kenagy, J., Liu, F., Soares, M.J., and Audus, K.L. Peptides 1998, 19, 1-8.

(44) Friedman, D. I., and Amidon, G.L. Pharm. Res. 1991, 8, 93-96.

(45) Thompson, S. E., and Audus, K.L. Peptides 1993, 15, 109-116.

(46) Muller, S., and Hochhaus, G. Pharm. Res. 1995, 12, 1165-1170.

(47) Schiller, P. W., Nguyen, T.M.D., Weltrowska, G., Wilkes, B.C., Marsden, B.J., Lemieux, C., and Chung, N.N. Proc. Natl. Acad. Sci. 1992, 89, 11871-11875. 


\begin{tabular}{|c|c|c|c|}
\hline Peptide & Amino Acid Composition & M.W. & $\begin{array}{l}\text { Permeability } \\
\text { coefficient } x \\
10^{5}(\mathrm{~cm} / \mathrm{sec})\end{array}$ \\
\hline DAMGO & Tyr-D-Ala-Gly-N-Me-Phe-Gly-ol & 513 & $11.90 \pm 2.90$ \\
\hline $\begin{array}{c}\text { Leu- } \\
\text { Enkephalin }\end{array}$ & Try-Gly-Gly-Phe-Leu & 537 & $9.57 \pm 4.63$ \\
\hline DALDA & Tyr-D-Arg-Phe-Lys- $\mathrm{NH}_{2}$ & 552 & $14.60 \pm 2.50$ \\
\hline TIPP- $\psi$ & Tyr-Tic $\psi\left[\mathrm{CH}_{2} \mathrm{NH}\right]-$ Phe-Phe & 618 & $5.99 \pm 0.62$ \\
\hline DADLE & Tyr-D-Ala-Gly-Phe-D-Leu & 624 & $7.49 \pm 1.44$ \\
\hline TIPP & Tyr-Tic-Phe-Phe & 634 & $4.93 \pm 0.60$ \\
\hline DSLET & Tyr-D-Ser-Gly-Phe-Leu-Thr & 641 & $4.53 \pm 2.89$ \\
\hline DPDPE & Tyr-[D-Pen-Gly-Phe-D-Pen](cyclic) & 645 & $6.56 \pm 0.97$ \\
\hline $\begin{array}{l}\text { Dynorphin A } \\
(1-8)\end{array}$ & Tyr-Gly-Gly-Phe-Leu-Arg-Arg-Ile & 1033 & $4.19 \pm 2.40$ \\
\hline $\begin{array}{c}\text { Dynorphin A } \\
(2-11)\end{array}$ & $\begin{array}{c}\text { Gly-Gly-Phe-Leu-Arg-Arg-Ile-Arg- } \\
\text { Pro-Lys }\end{array}$ & 1200 & $1.40 \pm 0.34$ \\
\hline $\begin{array}{c}\text { Dynorphin A } \\
(1-11)\end{array}$ & $\begin{array}{l}\text { Tyr-Gly-Gly-Phe-Leu-Arg-Arg-Ile- } \\
\text { Arg-Pro-Lys }\end{array}$ & 1363 & $0.23 \pm 0.04$ \\
\hline
\end{tabular}

Table 1

Apparent permeability coefficients for opioid peptide permeation across BeWo cell monolayers at $37^{\circ} \mathrm{C}$ 


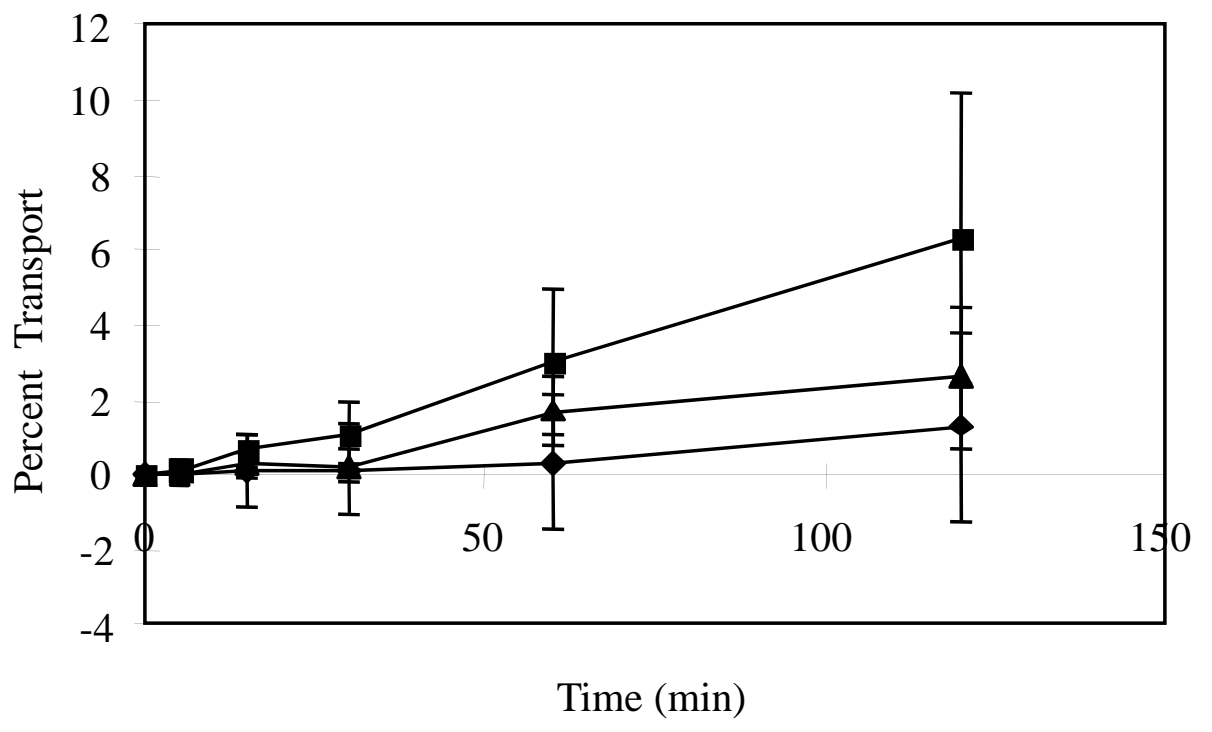

Figure 1

Effect of peptide size on permeation across the BeWo cell monolayers.

$\longrightarrow$ Dynorphin A (1-11); $\rightarrow$ Dynorphin A (1-8); $\rightarrow-$ Dynorphin A (2-11) 


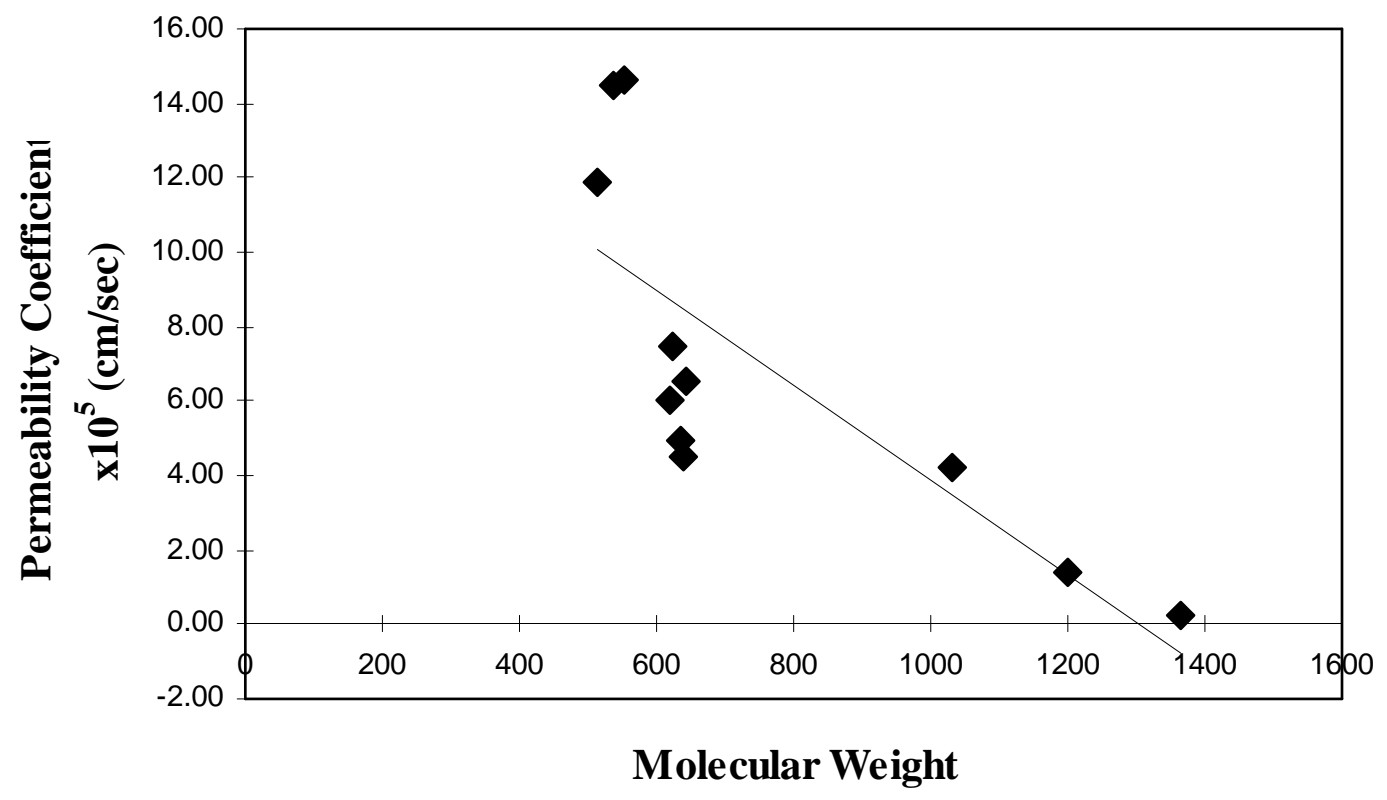

Figure 2

Plot showing the relationship between the molecular weights of model peptides and apparent permeability coefficients for permeation across BeWo cell monolayers 


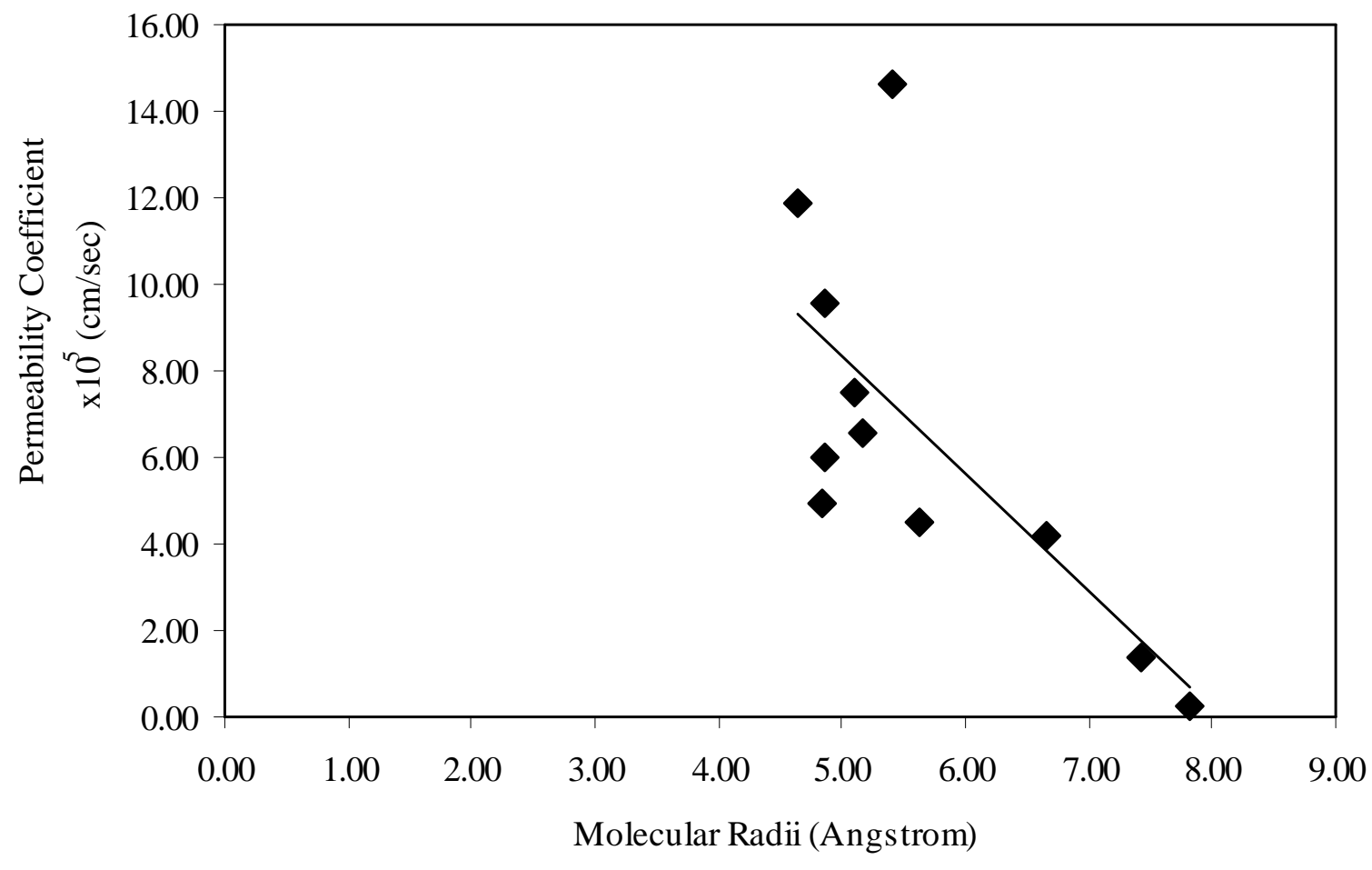

Figure 3

Plot showing the relationship between the molecular radii of model peptides and the apparent permeability coefficients for permeation across BeWo cell monolayers 


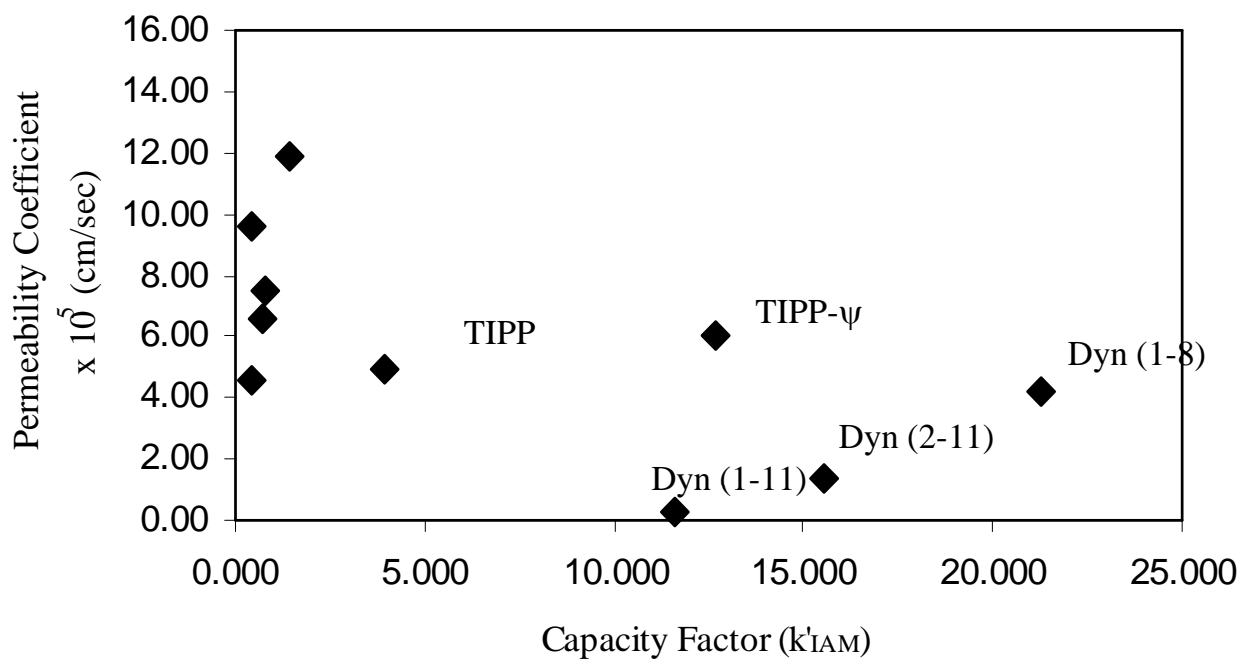

Figure 4a

Plot showing the relationship between the capacity factors $\left(\mathrm{k}_{\mathrm{IAM}}^{\prime}\right)$ and the permeability coefficients for opioid peptide permeation across BeWo cell monolayers

Chromatographic conditions: IAM (4.6 mm x $100 \mathrm{~mm}$, 300 A) column with $10 \%$ ACN in $10 \mathrm{mM}$ sodium phosphate buffer, $\mathrm{pH} 7.4$, UV detection at $210 \mathrm{~nm}$ 


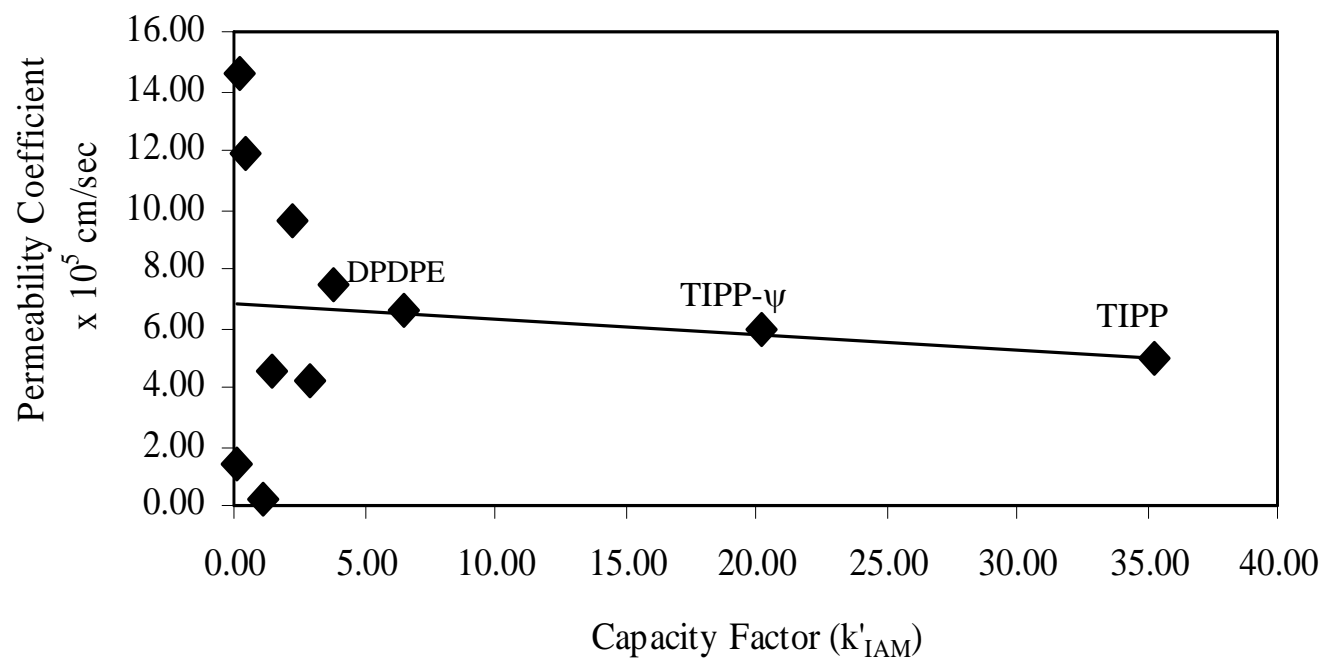

Figure $4 b$

Plot showing the relationship between the capacity factors ( $k_{\text {IAM }}^{\prime}$ ) and the permeability coefficients for opioid peptide permeation across BeWo cell monolayers

Chromatographic conditions: IAM (4.6 mm x 100 mm, $300 \AA$ ) column with $5 \%$ ACN in $10 \mathrm{mM}$ sodium phosphate buffer, $\mathrm{pH} 3.0$ and $2 \mathrm{mM}$ $1 H$-heptane sulfonic acid, UV detection at $210 \mathrm{~nm}$ 


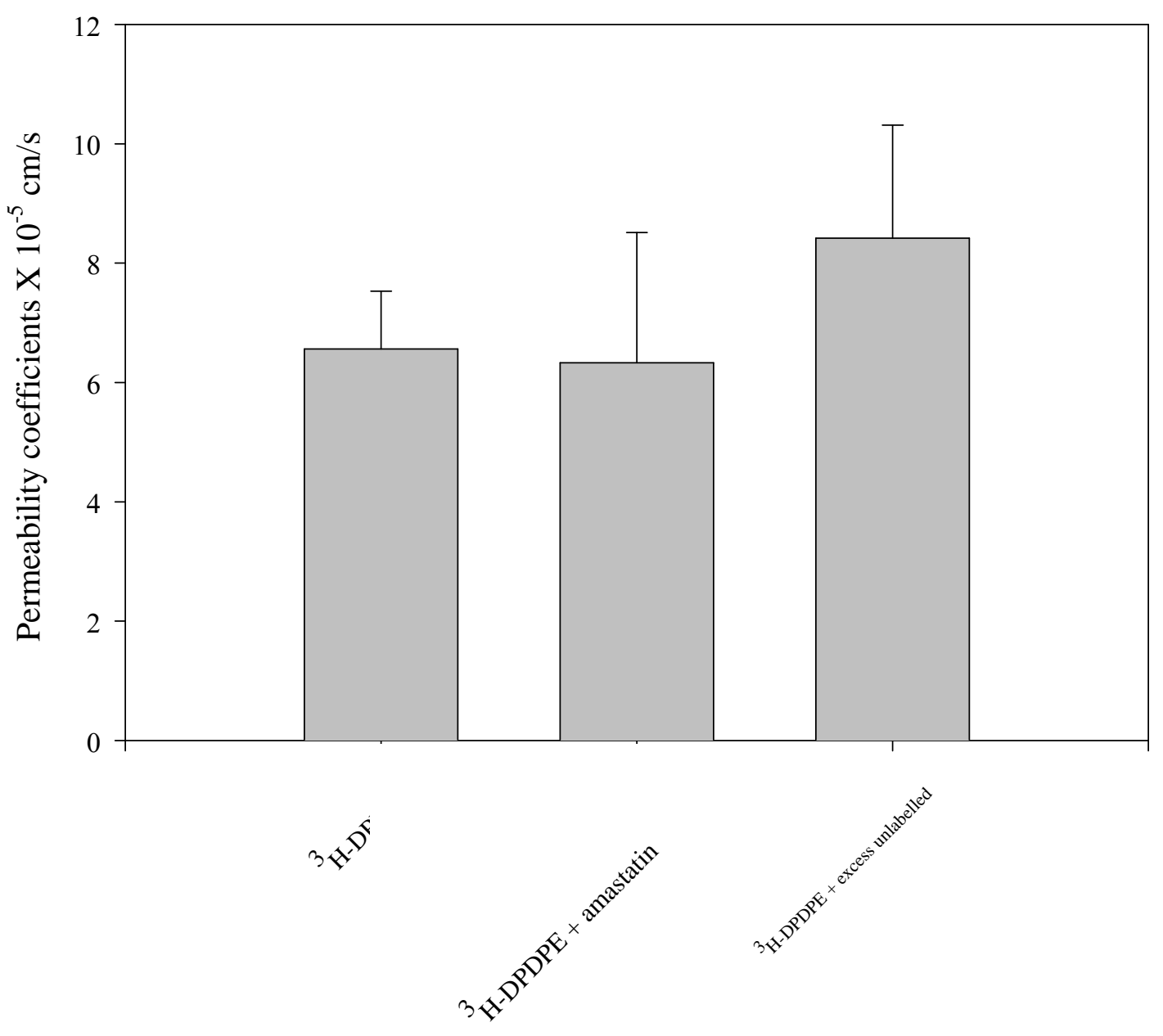

Figure 5 Guru's 


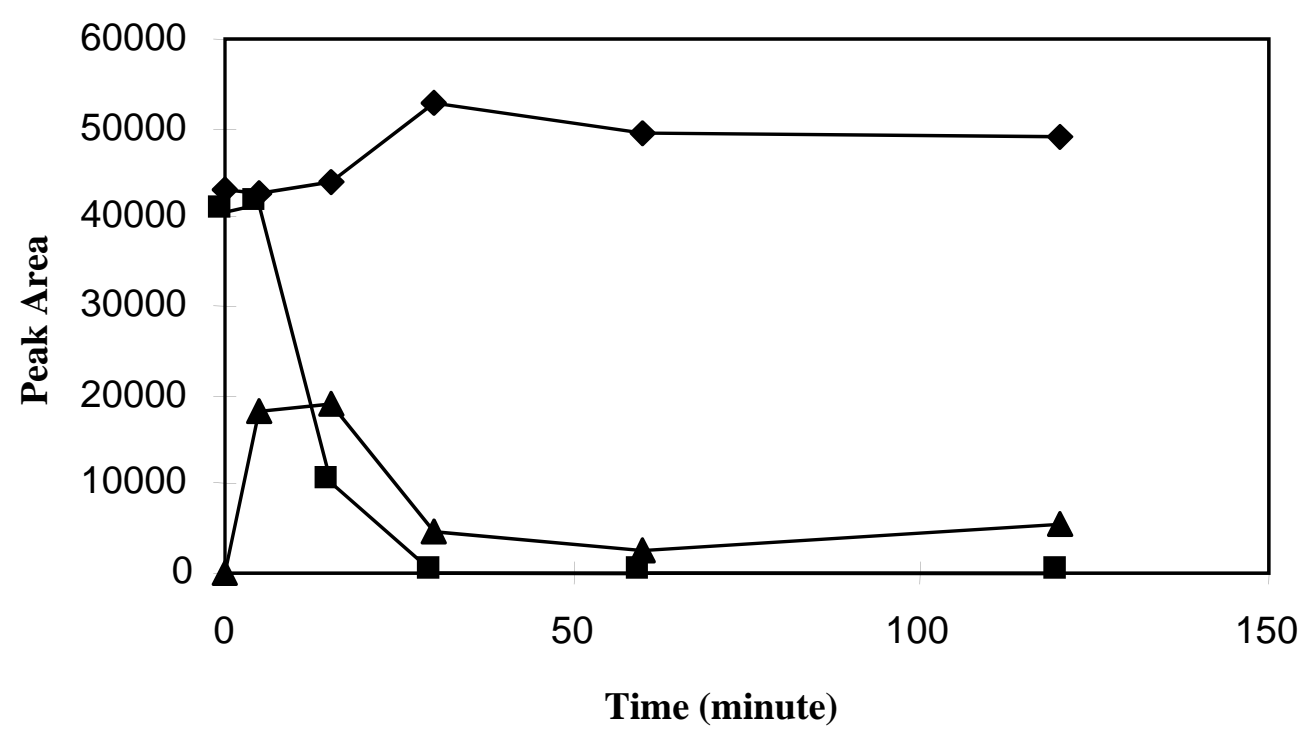

Figure 6

Stability of dynorphin A (1-11) upon the incubation with the BeWo cell monolayers, at $37^{\circ} \mathrm{C}$. $\sim$ control without cells; - samples with cells;

$\longrightarrow$ identified degradant [Dynorphin A (2-11)] 


\section{This one was shown in the ADDR paper}

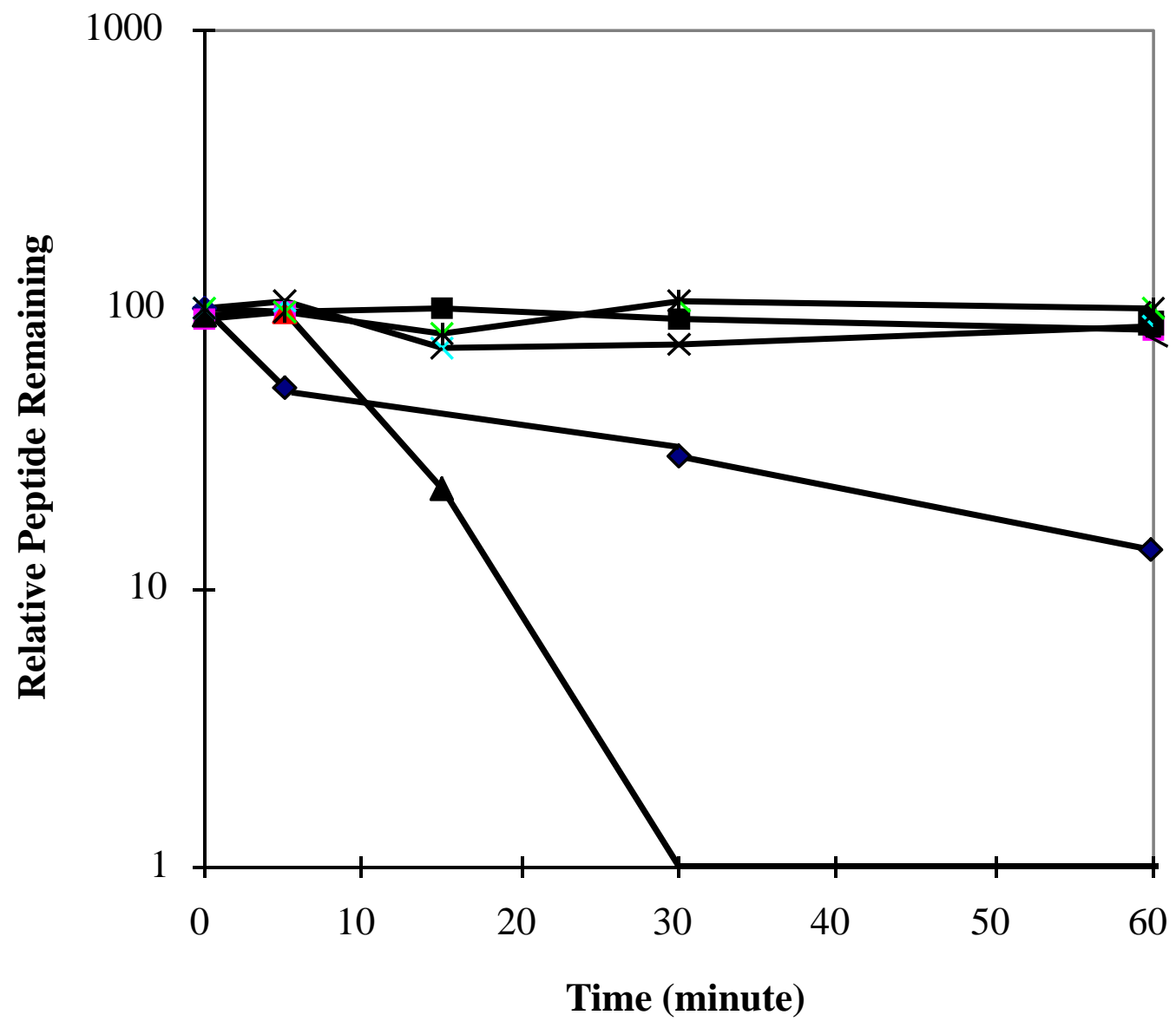

Figure 7

Stability of opioid peptides and analogues upon Incubation with BeWo cell monolayers, at $37^{\circ} \mathrm{C}$.

$\longrightarrow$ Leu-Enkephalin; $\rightarrow$ DADLE; $\rightarrow$ Dynorphin A (1-11)

$\rightarrow$ TIPP; $\rightarrow$ TIPP- $\psi$ 